\title{
Using Video Clips to Improve Oral Presentation Skills in Distance Learning Engineering Degrees and Master's Courses
}

\author{
Carlos Galindo, Pablo Gregori and Vicente Martínez \\ Universitat Jaume I, Dept. Matemáticas, Instituto Universitario de Matemáticas y \\ Aplicaciones de Castellón, Campus Riu Sec, 12071 Castellón, Spain. E-mails: \\ galindo@uji.es, gregori@uji.es,martinez@uji.es.
}

\begin{abstract}
In this paper we propose an active learning activity consisting of recording video clips as a tool to improve teaching on distance learning Engineering degrees and master's courses. On the one hand, these video clips improve the students' oral skills and, on the other hand, they are a good way of authenticating the students' identity when assessing them. To verify the advantages of our tool we carried out a pilot experiment with the students on a master's course. Each student recorded video clips in two phases (test and final versions) and used a rubric that we shared with them, with a satisfactory outcome in terms of motivation and academic results. It is also a very effective tool for checking the true authorship of the students' work.
\end{abstract}

\section{Introduction}

Important advances in ICTs over the last decade have greatly aided the development of distance education training programmes. This information is supported by several sources, and we can cite the 360,000 foreign students who followed distance learning courses at Harvard University in 2017 (Harvard, 2017). This should not be overlooked by other institutions, but must be taken seriously, since it will surely shape the way we teach in decades to come.

The overall goal of this work is to propose improvements in the teaching process, especially in distance learning Engineering degrees and master's courses, by using active learning tools. In particular, by recording video clips, where the student has to explain problem-solving tasks, projects and challenges posed in scientific subjects. A close experience for teachers has been described in Kersting (2008). Among other aims, we build a rigorous assessment procedure for students of these subjects on distance learning courses. We believe that this methodology can help raise public opinion about this type of courses; a Gallup poll in 2013 (Saad et al., 2013) showed that about 50\% of employers felt that the evaluation of distance learning was less reliable than that of faceto-face courses.

The production of an explanatory video clip requires a high conceptual control of the proposed task. It also involves cultivating a key skill that is rarely developed in scientific subjects and that is of great interest for students' future professional development: the ability to give oral presentations (Gray, 2010; Chan, 2011; Živković, 2014; Van Ginkel et al., 2015). This skill allows us to implement several generic competences belonging to the Tuning Project (Competences 3, 5, 18 and 27 in Wagenaar, 2018; see also Bultitude, 2011). Notice that the Tuning program is an effort to define a common terminology and common concepts for the planning, maintenance and description of programmes in European education. This program has contributed to enhancing the overall quality of the educational programmes offered by the European 
universities, in particular with respect to their relevance to the needs of society and of learners. It has broken a certain academic tradition focused on encyclopaedic knowledge restricted to a specific area enhancing the socio-economic relevance, more than the purely academic quality of the education (dale Rose and Haug, 2013). We teach mathematics and in this area, the international community considers the competence approach as an educational proposal that goes beyond the contents, and aims at the formation of constructive, committed and reflective citizens, allowing them to identify and understand the role played by mathematics in the world (OCDE, 2013). One of the contributions of the competence-based approach to the mathematics curriculum is to provide it with a structure oriented to the development of mathematical processes such like arguing, representing, calculating, modelling, solving problems and communicating (Solar et al., 2012).

We have put this methodology into practice in two subjects of the Master's Degree in Computational Mathematics of the School of Technology and Experimental Sciences at Universitat Jaume I in Castellón (Spain). The students had to solve a list of problems and were asked to record a video clip describing in detail how they had solved them. For the first version of the clip, students were intentionally left on their own and given no specific criteria or tools to help them. Teachers made a preliminary assessment, pointing out areas that could be improved, and provided the students with the detailed assessment rubric. We discarded, a priori, to introduce a peer feedback, because of the difficulty level of the mathematical task. Besides, authors such De Grez et al. (2009) question its effectiveness. In particular, the teachers stressed the importance of the students making their presentations rigorous and following a set of clear, logical guidelines. Mutual feedback about the choice of different video recording tools (software, devices, cloud services, etc.) was also found to be very enriching for both students and teachers. Finally, students were asked to produce a second version of the clip, which was the basis for the final evaluation of the activity.

The description of our experiment, together with a rubric, are presented in Section 2 of this paper, while the results are shown in Section 3. Our experiment yielded two important benefits. On the one hand, it helps students develop their ability to give oral presentations on scientific subjects. The deficit in higher education students in this aspect of education is well known (Chan, 2011), and we believe that this methodology will help reduce this deficit. On the other hand, it enables us to identify the student and confirms the authorship of the work. This improves the social perception of distance course certificates, since teachers have a higher level of control over their students' activities. The improvements resulting from our idea are shown in Section 4, where the conclusions of the work can be seen.

\section{Description of the experience}

In this paper we propose the idea of students on distance learning Engineering degrees and master's courses recording video clips. This has a two-fold purpose: firstly, to improve the oral skills of students on the aforementioned courses, and secondly, to provide an effective method of assessment that prevents impersonation. This is a difficult problem to solve in distance learning courses, where students are far from the teaching centre and find it difficult to attend examinations or tests in person. Additionally, it produces a deeper engagement of students in their learning (Guo et al., 
2014; Helme \& Clarke, 2001).

One can find some references supporting oral communication competence in the field of science and engineering. In this sense, Bhattacharyya (2014) notices the existence of interdisciplinary and interpersonal competences, among which there appears the ability to communicate, which is essential for engineers to be leaders in their professional field. She defends that the correct communication in oral technical presentations is a requirement that employers usually demand. Synergy and collaboration between academics and professionals are, according Bhattacharyya (2014), essential to ensure that the future graduates are encouraged to speak and engage in communications and work meetings in an effective manner. Another experience in this regard was those described in Greculescu et al. (2014). It carried out with a sample of 250 students in their third academic year in Computer Science, Electronics and Telecommunications, Electrical Engineering, Chemistry, or Mechanics. The purpose of the study was to identify the weaknesses and strengths of the engineering teaching staff when making oral presentations. The results helped to improve speech, avoid repetitions and increase motivation. Murillo-Zamorano and Montanero (2017) proceeded with a thorough study comparing the effect of peers and teacher feedback, in oral presentations of Economics and Bussiness students.

According to our proposal, in addition to the usual teaching of each subject the students carry out a number of tasks set by the teacher and record a video explaining the solution to these problems. Initially, they make the video on their own with no help from the teacher. Once submitted, the teacher assesses the work according to a previously prepared rubric, which will be explained below, and the teacher and the student's peers provide feedback based on the rubric (trying to adhere to the seven principles gathered in Van Ginkel et al., 2015). After this, the student submits a final version that is assessed once again, resulting in the student's final mark.

Although Murillo-Zamorano and Montanero (2017) conclude that single feedback is not effective in the long term, the different context of our experience (master's degree students; self-recorded video clip, instead of live presentation, that can be repeated until the student is satisfied; mathematical subjects). That is the reason why we are hopeful that only single feedback sessions produce improvement. On another note, a by-product of this methodology is the assurance of the authorship of assignments in distance education.

To determine how our proposal would work in practice, we performed an experiment at our university with students of the master's degree in Computational Mathematics at Universitat Jaume I in Castellón, Spain. Two subjects from the first semester of the 2017-2018 academic year were chosen, the teachers of which were interested in the proposed innovation: "Data mining" and "Mathematical methods for partial differential equations". There were 11 and 13 students in these groups, respectively, from all over the Spanish-speaking world. Until the previous academic year, the usual teaching method in these subjects consisted of master classes - recorded on video for distancelearning students - , supported by video tutorials by the teaching staff. The students were assessed evaluating an activity book containing a number of problems solved by each student.

This time, the student had the additional task of recording a video tutorial explaining 
how he/she solved certain problems set by the teachers. We design the problems, at least in part, for promoting the scientific inquiry whose main points could be stated as presenting questions and formulate hypothesis, planning a way to give an answer and adopt some strategy, which mainly will be to do experiments and collect data. Finally, the analysis of those data will provide evidences for our hypothesis. After this, we will use the above steps for giving a proof of our statement. Indeed, The American Association for the Advancement of Science (AAAS) asserted that "scientific inquiry [is not purely] doing experiments [or] making a great many careful observations and then organizing them" (AAAS, 1993). Teachers should encourage students to undergo a cognitive process, in a similar way scientists do, including present a question, form a hypothesis, design an exploration, acquire data, draw conclusions, redesign explorations, and lastly, form and revise theories.

An important aim of our additional task was to improve oral communication of scientific work (one of the key skills in this master's degree), as we believe that this skill is poorly developed in the current curriculum of scientific and technical studies. The preparation of the student's video also requires more profound knowledge of the concepts involved in the task, as it must be explained to others. Moreover, it allows us to overcome two of the drawbacks of distance learning: verifying the authenticity of the authorship of work submitted for assessment and preventing student dropout, as this follow-up and guidance by the teaching staff during the proposed activity encourages interaction and a closer relationship.

Before presenting their video, teachers gave some generic, not scientific, advices: preparing the presentation considering the audience (teachers), determining the purpose, doing research on the topic, selecting support material, organizing the speech, motivating the audience, and stating clear conclusions (Gareis, 2017; PennStUniv, 2017; Lortie, 2017; Fischhoff, 2013; Jucan \& Jucan , 2014). Students should look at a few areas that are relevant for a technical presentation: rate (the speed at which they speak), pauses (pauses serve two useful function because they allow the audience to absorb the information and they communicate emphasis), eye contact (look at the camera) and video yourself (you can often be your own best critic). Some other advices are provided: only one major point per slide, limit use of text, use simple visuals, repeat critical messages twice using different visuals, allocate more than one slide to effectively end the narrative, use the final slide for links to additional resources, and use timed practice.

For the first version of the video clip they were intentionally not provided with any criteria or tool. The teachers made a preliminary assessment, suggesting possible points for improvement: scientific accuracy, clarity of image and sound, choice of fonts, organization of the presentation and management of body language, among other aspects.

The aim of this feedback was to make the students aware of the importance of both speech and body language in an oral presentation. Although content is the most important thing when communicating ideas, structure, meaning and level of agreement with the interlocutor are also fundamental. Body language can convey much more information than words alone. Our gestures are constantly supplying information. Appearance, posture and facial expression convey a certain degree of reliability, level of knowledge and understanding of what one is saying. We believe that the first step in 
successful communication is to learn to identify the effect that it is having on others and on ourselves. In this regard, for each video presentation comments by the other students who have not taken part in the recording and assessment by the teachers can improve the original presentation considerably.

With regard to body language (see [5]), the teachers assessed the students on the basis of the following skills, among others:

- Self-awareness of behaviour. Communication improves when one is aware of the body language used, behaviour is monitored and its effect on others is calibrated.

- Emotional stability and empathy. These aid communication.

- Synchronization with speech. Focusing attention on the main channels of body language, endeavouring to use it coherently and in synchrony with the words. The volume, tone and speed of speech reveals important information, especially about our credibility.

- Monitoring communication channels. The appropriate channels should be chosen according to each situation and case. The main ones are facial expression, gestures, postures and appearance.

This feedback also assessed the student's creativity and initiative in terms of their choice of different video recording tools (software, devices, cloud services, etc.), which was very enriching for both the student and the teacher.

Of course, when correcting the students' presentations the teachers placed particular emphasis on errors made by the students in terms of not being sufficiently rigorous or not expressing scientific concepts with the necessary clarity.

Table 1. Rubric for oral communication by video

\begin{tabular}{|c|l|l|l|}
\hline Components & \multicolumn{1}{|c|}{ Sophisticated } & \multicolumn{1}{c|}{ Competent } & \multicolumn{1}{c|}{$\begin{array}{c}\text { Not Yet } \\
\text { Competent }\end{array}$} \\
\hline $\begin{array}{c}\text { Organization } \\
\left(\mathbf{w}_{\mathbf{1}}=\mathbf{0 . 1}\right)\end{array}$ & $\begin{array}{l}\text { Presentation is clear, } \\
\text { logical, and organized. } \\
\text { Listener can follow } \\
\text { line of reasoning. }\end{array}$ & $\begin{array}{l}\text { Presentation is clear } \\
\text { and organized, } \\
\text { except for a few } \\
\text { minor points. }\end{array}$ & $\begin{array}{l}\text { Presentation is } \\
\text { generally not clear } \\
\text { and disorganized. } \\
\text { Arguments are not } \\
\text { clear. }\end{array}$ \\
\hline $\begin{array}{c}\text { Image and } \\
\text { sound quality } \\
\left(\mathbf{w}_{\mathbf{2}}=\mathbf{0 . 0 5 )}\right.\end{array}$ & $\begin{array}{l}\text { Image is clear and } \\
\text { audience can hear the } \\
\text { speaker in any time. }\end{array}$ & $\begin{array}{l}\text { Image is clear and } \\
\text { audience can hear } \\
\text { the speaker, except } \\
\text { for a few moments. }\end{array}$ & $\begin{array}{l}\text { Image is not clear } \\
\text { and audience can } \\
\text { hear the speaker } \\
\text { with effort. }\end{array}$ \\
\hline $\begin{array}{c}\text { Communication tools } \\
\text { Text }\end{array}$ & $\begin{array}{l}\text { Font is readable. } \\
\text { Details are minimized } \\
\text { so that main points } \\
\left(\mathbf{w}_{\mathbf{3}}=\mathbf{0 . 1 )}\right.\end{array}$ & $\begin{array}{l}\text { Font is mostly } \\
\text { readable. Some } \\
\text { material is not } \\
\text { stand out. } \\
\text { aids. }\end{array}$ & $\begin{array}{l}\text { Font size is too } \\
\text { small. Details or } \\
\text { some important } \\
\text { information is } \\
\text { confused. }\end{array}$ \\
\hline $\begin{array}{c}\text { Accuracy } \\
\left(\mathbf{w}_{\mathbf{4}}=\mathbf{0 . 3 5}\right)\end{array}$ & $\begin{array}{l}\text { Information included } \\
\text { in the presentation is }\end{array}$ & $\begin{array}{l}\text { No significant } \\
\text { information errors }\end{array}$ & $\begin{array}{l}\text { Too many } \\
\text { information errors }\end{array}$ \\
\hline
\end{tabular}




\begin{tabular}{|c|l|l|l|}
\hline & $\begin{array}{l}\text { accurate (names, facts, } \\
\text { etc.). }\end{array}$ & are made. & $\begin{array}{l}\text { are made and } \\
\text { distract the } \\
\text { audience. }\end{array}$ \\
\hline $\begin{array}{c}\text { Verbal } \\
\left(\mathbf{w}_{\mathbf{5}}=\mathbf{0 . 3}\right)\end{array}$ & $\begin{array}{l}\text { Words express the } \\
\text { meaning precisely. } \\
\text { Sentences are } \\
\text { complete and } \\
\text { grammatical. }\end{array}$ & $\begin{array}{l}\text { Words express the } \\
\text { meaning and } \\
\text { sentences are } \\
\text { complete and } \\
\text { grammatical for the } \\
\text { most part. }\end{array}$ & $\begin{array}{l}\text { Some sentences are } \\
\text { incomplete and } \\
\text { have grammatical } \\
\text { errors. Vocabulary } \\
\text { is limited or } \\
\text { inappropriate. }\end{array}$ \\
\hline $\begin{array}{l}\text { Language } \\
\text { (wody }=\mathbf{0 . 1})\end{array}$ & $\begin{array}{l}\text { Body language } \\
\text { reflects comfort } \\
\text { interacting with } \\
\text { audience (gesture, } \\
\text { posture, appearance, } \\
\text { voice's tone, etc.) }\end{array}$ & $\begin{array}{l}\text { Body language } \\
\text { reflects some } \\
\text { discomfort } \\
\text { interacting with } \\
\text { audience. }\end{array}$ & $\begin{array}{l}\text { Body language } \\
\text { reveals a reluctance } \\
\text { to interact with } \\
\text { audience. }\end{array}$ \\
\hline
\end{tabular}

All of the above followed a detailed assessment rubric (see Table 1). Our rubric, based on the one introduced in $[1,3]$, assesses three levels of achievement for the following categories: organization of the presentation, image and sound quality, and communication tools (text, accuracy of content, verbal communication and non-verbal communication).

The rubric was presented to the students for their consideration when preparing the second version of the video clip, which was actually used for the final assessment of the activity. We have performed formative assessment as suggested in Fook \& Sidhu (2014). The final mark in this evaluation was obtained using a formula consisting of the following equation:

$$
M_{j}=\sum_{i=1}^{6} q_{i j} \cdot w_{i},(1)
$$

where $M_{j}$ is the mark obtained by student $j, w_{i}$ is the weighting of the category $i$ (see Table 1) and $q_{i j}$ is the score obtained ( 1 for Not Yet Competent, 2 for Competent and 3 for Sophisticated) by student $j$ in category $i$. Therefore, the final mark is a value between 1 and 3, with the possibility of students obtaining intermediate values between Not Yet Competent, Competent and Sophisticated.

The intention is to evaluate the student's skills, giving priority to the most important ones; this is essential for the student to feel fairly assessed and even allows them to have a hand in their own improvement. The rubric assesses different aspects and focuses on the development of students' oral communication skills. After the second version of the video had been assessed, an analysis was carried out to verify the effect of the proposed innovation.

\section{Results}

In our experiment, the first version of the video showed that students get high marks in the text, accuracy and verbal communication sections, but the lowest scores are obtained 
for non-verbal communication (very low, close to the lowest level) and organization (not so poor, but close to the intermediate level) - see Fig. 1, left-. In summary, master's students are good speakers in terms of quality of content and writing, but the speech is markedly dull and discouraging for listeners. We believe that this is because master's students have already achieved an undergraduate degree and have mastered the theoretical aspects of the content presented. What is more, some of them are secondary school teachers who are extending their training by studying a master's degree, so they can express themselves well and are reasonably rigorous. In view of our teaching experience in the university setting, it seems clear that we would obtain worse results with new students on the current undergraduate programmes, which would make experiments of this type even more valuable.

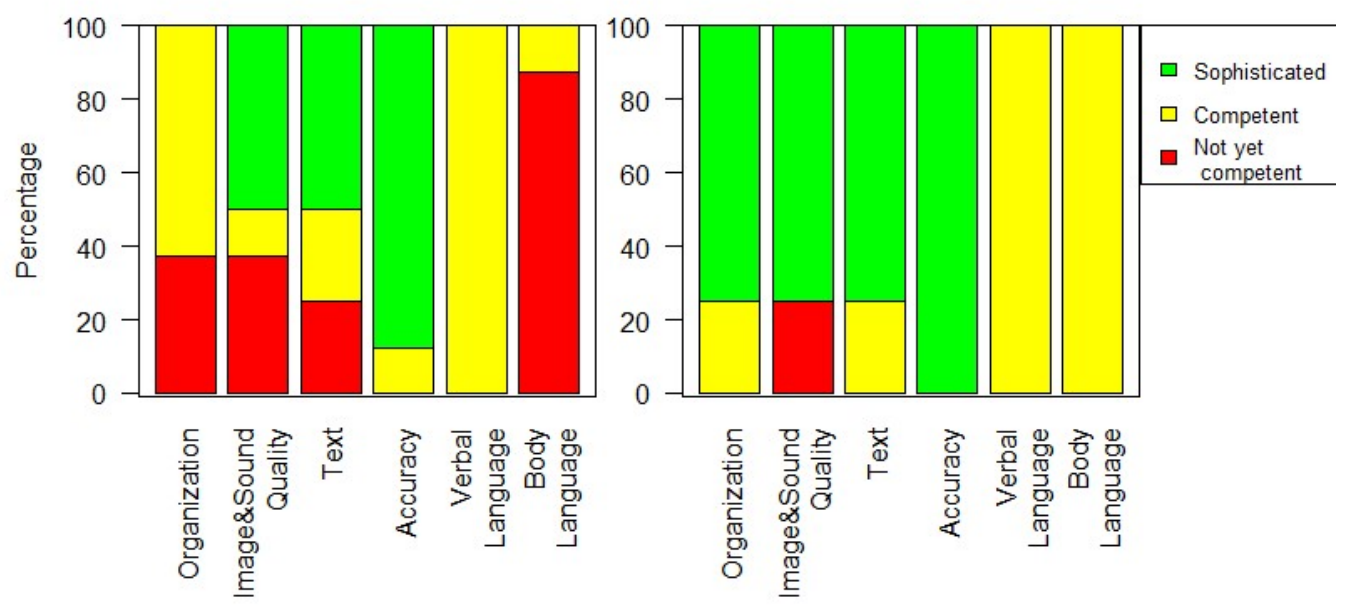

Figure 1: Scores for the first (left) and second (right) version of the video.

After receiving the teacher's feedback and with a knowledge of the rubric that would be applied, the students recorded the second version of the video, incorporating the suggested improvements in terms of both the task and technology or tools. The results are shown in Fig. 1 (right).

Fig. 2 shows the evolution of the students' average scores from the first to the second version of the video, for each aspect of the rubric. After the teacher's feedback, the score for the "Organization" and "Body Language" sections has improved significantly. In addition, the many comments made by peers (in the online forum) have shown students' enthusiasm for the experience and satisfaction with the final results. The activity has also given students greater opportunities to socialize with each other, which is important in the case of distance courses, as they are usually cut off and unaware of their peers. Obviously, the improvement in the "Image \& Sound Quality" aspect was not substantial because the distance learners had very limited technical resources. 
Evolution of grades

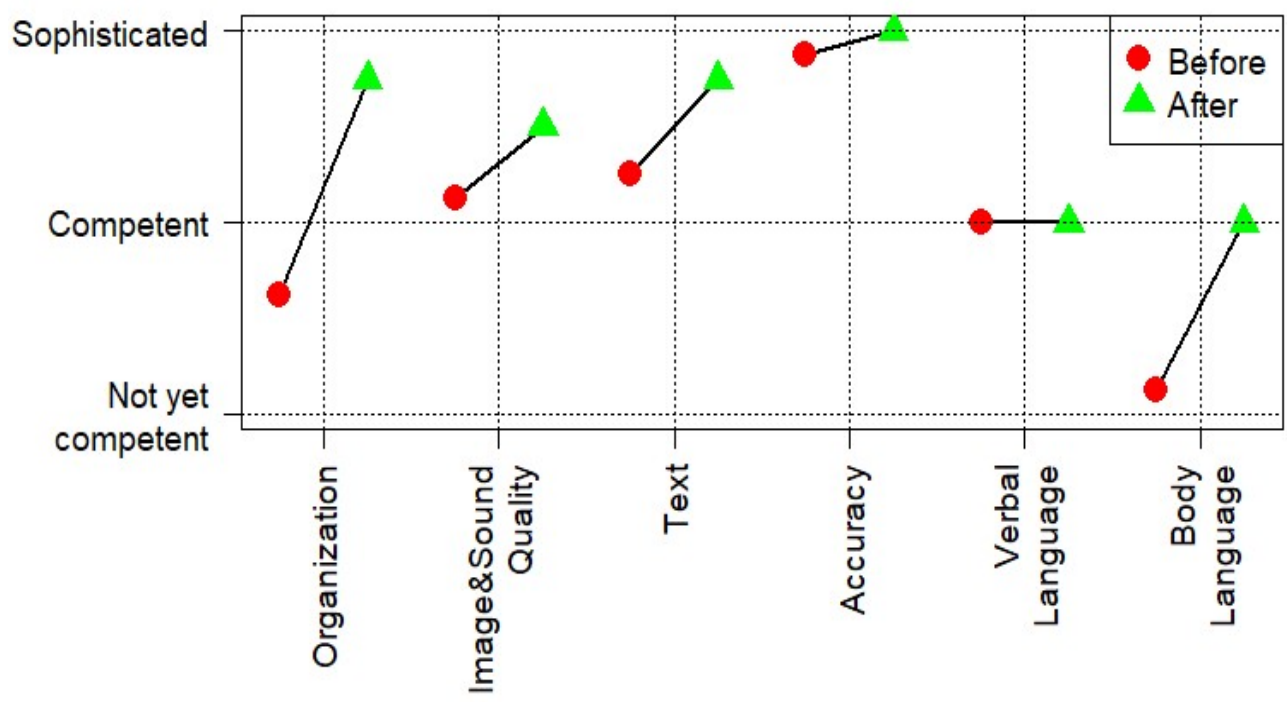

Figure 2: Evolution of the students' scores from the first to the second version of the video

Some of the students recorded the video on their mobile telephone, some with a webcam and one student even used a high-resolution camera and wrote on an appropriate sized board, thus offering professional quality and clarity.

Based on the intuitive evidence provided by Fig. 2, we wanted to check in which aspects of the rubric the improvement brought about by the feedback had been significant, in order to reject the effect of pure chance. To do this, we performed a nonparametric statistical hypothesis test, the sign test [7]. This comparison returns a pvalue, which is regarded as the probability that the sample obtained is compatible with the null hypothesis "Improvement due to pure chance". Normally, when this p-value is less than $5 \%$, the null hypothesis is rejected on the grounds that some effect out of pure chance has taken place.

- In the "Organization" aspect, a statistically significant improvement was observed. Against the null hypothesis that the feedback did not cause any positive effect on learning, the comparison yielded a p-value of $0.7 \%$, which clearly shows that the improvement does not depend on chance.

- In the "Image \& Sound Quality", "Text" and "Accuracy" aspects, there were some improvements, but they were not conclusive, given the good initial level of the students in these aspects.

- In the "Verbal Language" aspect, there was no improvement in any case. All the students had a considerable level of skill, but they did not reach the maximum level either before or after interactions with the teacher.

- Lastly, there was a substantial improvement in the "Body Language" aspect. The comparison yielded a p-value of $0.6 \%$, so we can assert that there was a statistically significant improvement.

With regard to the academic results, Fig. 3 clearly shows a positive evolution of the 
marks and a reduction in dispersion after the students received guidance from the teaching staff. The activity was marked according to the rubric, using the weights assigned in Table 1 to highlight the most important aspects. The overall calculation of the mark was obtained using Eq. (1).

Finally, we also found that our experiment was valuable for confirming the students' identity, since, apart from the much lower likelihood of someone else impersonating the students in this activity, the interaction with them between the test version and the final version hugely reduced the possibility of the final assessment of the subject not matching the students' actual level.

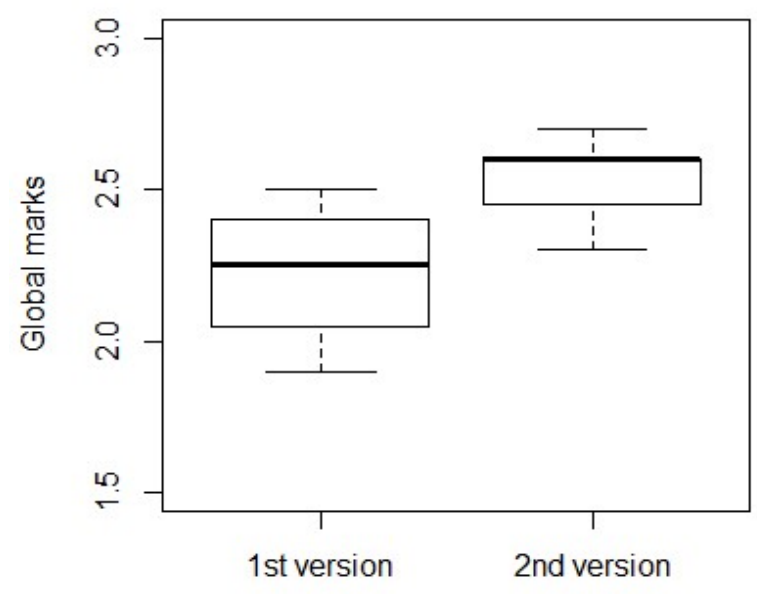

Figure 3: Boxplot of global marks obtained by students in the 1st and 2nd version of the video clip.

\section{Conclusions}

The experiment conducted has been enriching for both students and teachers. The main objective was to develop a skill that is largely neglected in the curricula of scientific and engineering subjects, but which is very important from a professional point of view: the ability to give oral presentations. To do this, an "active learning" activity was designed, consisting of recording video clips that were assessed using a rubric, which helped the students develop this skill thanks to the aspects assessed. It also provided a more objective method for marking the students' work and prevented the possibility of other people impersonating them.

A very significant improvement was observed in the "Organization" and "Body Language" aspects. The results and statistical tests performed clearly show this, as the scores in these aspects increased from 1.62 to 2.75 (respectively from 1.12 to 2.00 ).

In the "Image \& Sound Quality" aspect, a great diversity of resources was used, one of which was highly professional; however, in three cases the quality was low. This is undoubtedly due to the diversity of students, the economic resources available to them, their geographical area, etc. and therefore not related to the student's academic abilities. 
The score increased from 2.12 to 2.50 .

With regard to "Verbal Language", despite having an acceptable level, no evolution was observed. In both cases the mean score was 2. This encourages us to continue with this type of activities, increasing the number and diversity of problems, as there is room for improvement.

A secondary but no less important objective has also been achieved; as such activities increase the students' use of new technologies and mobile devices in relation to their learning process.

In summary, based on the data obtained from our experience, we conclude that, with respect to previous academic years, there have been improvements in the following points: student satisfaction with the proposed subjects, promotion of companionship among distance students, academic results, teacher control over the authorship of the students' work and promotion of ICT and mobile devices.

We end up by proposing some suggestions for improvement in future applications. To begin with, institutions should engage in these kind of active learning practices, by providing their teachers with sufficient technological resources (human and material), and not letting it to their good will. In addition, special care should be put in the selection of problems (in order to be highly motivating for students). We also consider that it is worthier to ask them to produce several separate shorter videos, rather than to prepare a few longer ones. Furthermore, teachers should be approachable and encourage students to ask them for assistance at any time, as well as remind them to work harder on the first version of the video (we have appreciated deficiencies on that side, students usually go their way before the first feedback). And last, but not least, another suggestion is the introduction of gamification in this activity, by putting, for instance, a peer system of scored feedback assessment, attractive milestones, and some other means, as in Zhu et al. (2017).

\section{References}

1. AAAS, American Association for the Advancement of Science (1993). Benchmark for science literacy: Project 2061. New York: Oxford University Press.

2. R.B. Adler and N. Towne, Looking out/looking in: Interpersonal communication (8th ed.). New York: Harcourt Brace College Publishers, 1996.

3. E. Allen and J. Seaman, Grade Level: Tracking Online Education in the United States. Babson Survey Research Group and Quahog Research Group, LLC. Retrieved from: http://www.onlinelearningsurvey.com/reports/gradelevel.pdf, Accessed 10 July 2017.

4. E. Bhattacharyya. Technical Oral Presentations of Engineers in the 21st Century, Procedia-Social and Behavioral Sciences 123 (2014) 344-352

5. K. Bultitude, The Why and How of Science Communication. In: Rosulek P, editor. Science Communication. Europe: Pilsen: European Commission; 2011.Harvard University, http://www.harvard.edu/about-harvard. Accessed 10 January 2018.

6. Chan, V. 2011. "Teaching Oral Communication in Undergraduate Science: Are 
We Doing Enough and Doing It Right?" Journal of Learning Design 4 (3): 7179.

7. De Grez, L., M. Valcke, and I. Roozen. 2009a. "The Impact of an Innovative Instructional Intervention on the Acquisition of Oral Presentation Skills in Higher Education." Computers and Education 53 (1): 112-120.10.1016/j.compedu.2009.01.005

8. B. Fischhoff, The sciences of science communication. Proceedings of the National Academy of Sciences 110:14033-9 (2013).

9. C. Y. Fook and G. K. Sidhu Assessment Practices in Higher Education in United States. Procedia-Social and Behavioral Sciences 123, 299-306 (2014).

10.E. Gareis, Guidelines for Public Speaking. Available at http://www.baruch.cuny.edu/tutorials/weissman/oral presentations/public speak ing guidelines.pdf.

11. Gray, F. E. 2010. "Specific Oral Communication Skills Desired in New Accountancy Graduates.” Business Communication Quarterly 73 (1): 40-67, DOI: $10.1177 / 1080569909356350$

12. Greculescu et al. Oral communication competence and higher technical engineering, Procedia-Social and Behavioral Sciences 128 (2014) 161-174.

13. Guo, P.J., Kim, J., \& Rubin, R. (2014) How video production affects student engagement: An empirical study of MOOC videos. L@S 2014 - Proceedings of the 1st ACM Conference on Learning at Scale, pp. 41-50. doi: $10.1145 / 2556325.2566239$

14. Helme, S., \& Clarke, D. (2001) Cognitive Engagement in the Mathematics Classroom. Springer, Netherlands.

15. M. E. Huba and J. E. Freed, Learner-centered assessment on college campuses: Shifting the focus from teaching to learning, Allyn \& Bacon: Needham Heights, MA, 2000, pp. 156-157.

16. M.S. Jucan, C.N Jucan. The Power of Science Communication. Procedia-Social and Behavioral Sciences 149:461-6 (2014).

17. N. Kersting, Using Video Clips of Mathematics Classroom Instruction as Item Prompts to Measure Teachers' Knowledge of Teaching Mathematics, Educational and Psychological Measurement, 68 (5), 2008, pp. 845-861.

18. C. J. Lortie, Ten simple rules for short and swift presentations. PLoS Comput Biol 13 (2017).

19. S. Lucas, The art of public speaking. Boston: McGraw-Hill. Osborn, M., \& Osborn, S. (latest edition). Public speaking. New York: Houghton Mifflin, 2015.

20. L. R. Murillo-Zamorano, M. Montanero (2017) Oral presentations in higher education: a comparison of the impact of peer and teacher feedback, Assessment \& Evaluation in Higher Education, 43(1), 138-150, DOI: 10.1080/02602938.2017.1303032

21. OCDE (2013). PISA 2012 Assessment and Analytical Framework: Mathematics, Reading, Science, Problem Solving and Financial Literacy. OECD Publishing, 2013.

22. A. Pease, The definitive book of body language, Orion Publishing, London, 2006.

23. Penn State University. Effective presentations in Engineering and Science. Available at http://www.engr.psu.edu/speaking/DELIVERY.html

24. L.F.D. dale Rose and G. Haug, Programme Profiles and the Reform of Higher Education

in Europe: The Role of Tuning Europe, Tunning Journal for Higher Education 
1, (2013), 203-222.

25. L. Saad, B. Busteed and M. Ogisi, Online Education Rated Best for Vale and Options. A Gallup Poll Survey. Retrieved from: http://www.gallup.com/poll/165425/online-education-rated-best-valueoptions.aspx, Accessed 11 November 2017.

26. H. Solar, C. Azcárate and J. Deulofeu, Competencia de argumentación en la interpretación de gráficas funcionales. Enseñanza de las Ciencias 30 (2012) 133-154 (in Spanish).

27. Van Ginkel, S., J. Gulikers, H. Biemans, and M. Mulder. 2015. "Towards a Set of Design Principles for Developing Oral Presentation Competence: A Synthesis of Research in Higher Education." Educational Research Review 14: 62-80, DOI: 10.1016/j.edurev.2015.02.002

28. R. Wagenaar, Generic Competences in Tunning Education Structures in Europe, available at http://www.unideusto.org/tuningeu/competences/generic.html

29. F. Wilcoxon, Individual Comparisons by Ranking Methods, Biometrics Bulletin 1 (6), 1945, pp.80-83.

30. Živković, S. 2014. "The Importance of Oral Presentations for University Students." Mediterranean Journal of Social Sciences 19 (5): 468-475. doi:10.5901/mjss.2014.v5n19p468

31. Zhu Y., Pei L., Shang J. (2017) Improving Video Engagement by Gamification: A Proposed Design of MOOC Videos. In: Cheung S., Kwok L., Ma W., Lee LK., Yang H. (eds) Blended Learning. New Challenges and Innovative Practices. ICBL 2017. Lecture Notes in Computer Science, vol 10309. Springer, Cham. 